\title{
Aqui se faz política, ali só se dança: criação de fronteiras discursivas entre participantes da Parada LGBT de São Paulo na mídia jornalística brasileira
}

\author{
Here politics is done, there is only dancing: creation of discursive boundaries between \\ participants of the LGBT Pride Parade in São Paulo in the Brazilian journalistic \\ media \\ Victor Augusto Menezes RIBEIRO* \\ Universidade do Estado do Rio de Janeiro (Uerj) \\ Poliana Coeli Costa ARANTES** \\ Universidade do Estado do Rio de Janeiro (Uerj)
}

\begin{abstract}
RESUMO: Desde sua criação, a Parada LGBT de São Paulo sofreu transformações significativas em sua organização, ganhando feições bastante próprias. Assemelhando-se em sua primeira edição ao que poderia ser compreendido como uma manifestação prototípica, com seu crescimento, sua atuação parece "carnavalizar-se progressivamente", sugerindo modos diversos do fazer político. Essa organização tem impacto sobre sua recepção pela sociedade e pela mídia jornalística. Neste trabalho, através de elementos mobilizados pela Análise do Discurso de linha francesa, investigamos como o discurso jornalístico "captura" o político, limitando-o a lugares delineados, criando fronteiras discursivas entre participantes. Tomamos como corpus um recorte quadrienal, de 1997 a 2013, em notícias da Folha de São Paulo sobre a manifestação, observando o tratamento dado aos indivíduos e grupos presentes (e ausentes) no evento. Os achados sugerem a predominância de uma política territorializada, ainda que a malha discursiva permita linhas de fuga para outros modos de se fazer política na Parada.
\end{abstract}

PALAVRAS-CHAVE: Parada do Orgulho LGBT. Política. Discurso jornalístico.

\begin{abstract}
Since its creation, the LGBT Pride Parade in São Paulo has undergone significant transformations in its organization, gaining own features. Resembling in its first edition what could be understood as a prototypical manifestation, with its growth, its performance seems to be "carnivalizing progressively," suggesting different ways of political doing. This organization has an impact on its reception by society and the news media. In this work, through French Discourse Analysis, we investigate how the journalistic discourse "captures" the political, limiting it to delineated places, creating discursive boundaries between participants. We took as a corpus a quadrennial cut, from 1997 to 2013, in Folha de São Paulo news about the manifestation, observing the treatment of individuals and groups present (and absent) in the event. The results suggest a predominance of a territorialized policy, although the discursive mesh allows lines of escape for other ways of doing politics in the Pride Parade.
\end{abstract}

KEYWORDS: LGBT Pride Parade. Politics. Journalistic discourse.

\footnotetext{
* Mestre em Linguística (2016) pelo Programa de Pós-Graduação em Letras da Universidade do Estado do Rio de Janeiro. Contato: vsribeiro26@gmail.com

** Doutora em Linguística (2013) pelo Programa de Estudos Linguísticos da Faculdade de Letras da Universidade Federal de Minas Gerais, com período de doutorado sanduíche (bolsa CAPES/DAAD) na Albert-Ludwigs-Universität Freiburg (Alemanha). Professora adjunta de Língua e Literatura Alemã da Universidade do Estado do Rio de Janeiro, atuando no Programa de Pós-Graduação em Letras (mestrado e doutorado em Linguística). Contato: polianacoeli@yahoo.com.br
} 


\section{Introduçãã ${ }^{2}$}

Em 1969, em frente ao bar gay Stonewall Inn, em Nova York, acontece o que será reconhecido por muitos como o primeiro movimento de indivíduos não heterossexuais de luta por seu direito à diferença (RIBEIRO, 2011): após uma abordagem violenta no bar pela polícia local, gays, lésbicas, travestis e drag queens se unem para reagir contra a discriminação. Ao redor do mundo, convencionou-se enxergar nesse ato o pontapé inicial para as Paradas gays (modernamente chamadas de Paradas LGBT ${ }^{3}$ ).

No Brasil, anos depois, começam as primeiras articulações de um movimento de gays, lésbicas, bissexuais e travestis, inicialmente nos anos 1970, com a fundação do grupo Somos (FACCHINI, 2011). Antes de uma articulação política propriamente dita, o que havia eram "guetos", locais com maior propensão à circulação de homossexuais, travestis e transgêneros, como bares, clubes, bailes de carnaval, etc. Desse modo, tal movimento surge em contraste com certos espaços de "sociabilidade", o que sugeriria uma tensão interna ao movimento entre espaços ditos "politizados" e "não politizados". Ainda assim, as atividades de sociabilidade e lazer não desaparecem por completo, sendo muitas vezes conjugadas com reuniões de grupos militantes (sobretudo em São Paulo), de modo que as duas tendências viriam a influenciar a adesão às Paradas do Orgulho LGBT no Brasil (FACCHINI; FRANÇA, 2009, p. 60).

Em 1980, com a ampliação da atuação do movimento, acontece a primeira manifestação reconhecidamente organizada em favor da causa gay no país, uma passeata contra o delegado Wilson Richetti, cujas ações de "limpeza urbana" visavam "tirar das ruas os pederastas, maconheiros e prostitutas" (TREVISAN, 2006, p. 14).

Ainda nessa década, o movimento brasileiro conhece um período de aumento da visibilidade da homossexualidade, graças ao surgimento de um mercado de bens e serviços voltados para o público gay e também em razão da epidemia de Aids (FACCHINI, 2005; 2011). Diminuído o pânico provocado pela doença (FACCHINI,

\footnotetext{
${ }^{2}$ Este trabalho é um recorte de dissertação de Mestrado intitulada "Fronteiras do político em notícias sobre a Parada do Orgulho LGBT de São Paulo" defendida no Programa de Pós-Graduação em Letras da Universidade do Estado do Rio de Janeiro, em 2016, de autoria de Victor Ribeiro, sob orientação da Profa. Dra. Poliana Arantes.

${ }^{3}$ A questão do nome do movimento é objeto de discussão de inúmeras publicações, dentre as quais destacamos a de Facchini (2005). Sem ignorar as recentes discussões sobre o tema, adotaremos aqui a sigla LGBT, usada mais modernamente pelos organizadores da Parada para nomear o evento.
} 
2011), o chamado "mercado GLS" torna-se "locus central para o ativismo homossexual", sobretudo na cidade de São Paulo, ao longo dos anos 1990 (RAMOS; CARRARA, 2006), associando direitos e consumo.

É somente no final dos anos 1990 que o Brasil conhece suas primeiras Paradas LGBT propriamente ditas. No Rio de Janeiro, em 1995, acontece a Marcha pela Cidadania de Gays, Lésbicas e Travestis, após o encerramento da $17^{\mathrm{a}}$ Conferência Anual da ILGA - Associação Internacional de Gays, Lésbicas e Travestis. Em 1997, a primeira Parada GLT - nome do evento na ocasião - se organiza com aproximadamente duas mil pessoas (400, segundo a mídia local), na praça Roosevelt, centro da cidade.

Desde o início, o objetivo principal da Parada gira em torno da estratégia de visibilidade massiva da homossexualidade, incluindo-se, em um ano ou outro, questões voltadas para a cidadania, conquistas de direitos legais, pressões para leis antihomofobia, etc. Contudo, essa visibilidade engendra uma relação particular entre cidadania e consumo, com empresários do nicho "GLS" investindo no chamado "pink money" - economia movimentada por bens e serviços voltados para um público de gays, lésbicas, travestis e transgêneros. Com isso, surge "uma nova postura entre o público consumidor, que atua na garantia de seus direitos ao consumo como um caminho para a conquista de cidadania" (FACCHINI; FRANÇA, 2009, p. 61).

Tal postura não vem sem consequências. Em 1999, bares e boates passam a financiar trios elétricos na Parada, o que altera profundamente sua organização. $\mathrm{Na}$ visão de alguns, passa-se “de uma denúncia política militante (embora lúdica) para uma celebração explosiva e incontida do orgulho gay, tão entusiasmada e extravagante a ponto de poder ser considerada um carnaval fora de época em pleno sudeste do Brasil" (BUTTERMAN, 2012, p. 37). Além disso, nos anos posteriores, a Parada passa a receber apoio público, do Ministério da Saúde e da Prefeitura de São Paulo (em 2000), e da iniciativa privada (em 2001). Hoje, diversas instituições se inserem entre os financiadores da Parada, desde empresas de preservativos a canais de TV.

O que parece ocorrer, portanto, é uma dinâmica retroalimentada: ampliando-se a visibilidade da manifestação, amplia-se pari passu o interesse em se injetar capital privado e estatal no evento, movimentando mais dinheiro e permitindo o desenvolvimento da manifestação ${ }^{4}$.

\footnotetext{
${ }^{4}$ Em 2007, a Parada LGBT de São Paulo foi responsável por aproximadamente $10 \%$ do faturamento
} 
$\mathrm{Na}$ medida de seu crescimento, bem como de sua visibilidade midiática, acaloram-se as discussões sobre sua aparente "despolitização", as quais dividem, inclusive, o próprio movimento. Apontam-se, de um lado, práticas políticas de cunho mais "festivo", vistas como menos "aborrecidas" e podendo proporcionar aos militantes uma ampliação de seu espaço social e político e questionar a ordem estabelecida ao mesmo tempo em que expressam reivindicações (PARIS, 2015); de outro, ações mais “incisivas", nas quais a tônica seja dada pela reivindicação em si. Com efeito, em 2014, no Rio de Janeiro, uma manifestação convocada pela internet, intitulada "Nova Parada LGBT", prerrogava justamente um foco maior sobre as pautas do movimento, alheio à festa identificada na Parada “oficial” (PARIS, 2015).

Frente ao exposto, encontramos em Butterman (2012, p.82) um questionamento que ecoa neste artigo: "Será que não há uma dimensão política também na ação de drag queens e participantes fantasiados? Ou seja, por que a tendência em considerar a dimensão festiva como antipolítica?”. De fato, Silva (2006 apud PARIS, 2015, p. 96) identifica na Parada uma "reestruturação na forma de manifestação política, com a aproximação da festa à política, prática até então impensável”, e que se coaduna com certa disposição em associar a práxis política à estética, no movimento LGBT (COTTA; CABRAL FILHO, 2015).

Por essa razão, interessa-nos verificar a intervenção do discurso jornalístico sobre a "realidade" da Parada. Assim, apontamos como objetivos responder aos seguintes questionamentos: que subjetividades estão sendo produzidas para os participantes (e não participantes) da Parada LGBT em notícias sobre a manifestação? De que forma isso permite separar "lugares de política" dentro dela? Que mecanismos linguísticos e discursivos permitem capturar o político, distinguindo-o e isolando-o de certa "prática festiva"? Como o fazem? Teria havido deslocamentos de sentidos para a política na Parada desde o início de sua cobertura?

\section{Aspectos teórico-metodológicos}

Duas razões levaram à seleção do jornal escolhido como corpus desta investigação: sua circulação nacional e sua possibilidade de cobrir "diretamente" o

anual da cidade com turismo e hotelaria (MACHADO; PRADO, 2007, p. 253). 
evento, reduzindo ao máximo os intermediadores na tríade acontecimento-jornal-leitor (sendo o que chamamos de "jornal", aqui, é entendido como uma entidade compósita, com múltiplos atores, que vão desde o jornalista aos princípios editoriais do periódico). Assim, selecionamos a Folha de São Paulo, em razão de sua posição de destaque entre os jornais mais vendidos no país (INSTITUTO VERIFICADOR DE COMUNICAÇÃO, 2015) e sua localização na cidade da Parada em questão, dispensando agências de notícias para a mediação e transmissão de informações sobre o evento.

Buscando observar a maneira como o jornal "apresenta a realidade" ao público (“aconteceu isto"), analisamos as reportagens publicadas no dia seguinte ao evento. Para tanto, servimo-nos do mecanismo de busca do acervo digitalizado do sítio eletrônico do jornal. Em seguida, realizamos uma leitura do material coletado, em conjunto com o referencial teórico das noções de pressupostos e subentendidos de O. Ducrot (1987) e dos conectivos argumentativos teorizados pelo mesmo autor e retomados por D. Maingueneau (1997) sob a perspectiva da Análise do Discurso.

Num segundo momento, efetuamos um levantamento temático das notícias ${ }^{5}$, verificando repetições de temas e personagens, de modo a estabelecer as categorias de análise: discurso relatado, relato do evento e caracterização dos participantes.

Frente às categorias, confrontamo-nos com a inviabilidade de um trabalho satisfatoriamente aprofundado, devido à sua extensão, considerando a fecundidade dos aportes teóricos evocados. Assim, realizamos um segundo recorte que permitisse reduzir a quantidade de notícias sem perder o acompanhamento longitudinal da Parada. Determinamos o ano de 1997 como marco inicial do acompanhamento (primeira edição da manifestação), adotando um intervalo de quatro anos entre as edições: 2001 (uma notícia), 2005 (duas), 2009 (duas) e 2013 (três), totalizando nove notícias.

A opção pelo intervalo se relaciona também com a recorrência das eleições para os cargos de presidente, governador, senador e deputados (federal e estadual), garantindo que todas as reportagens fossem publicadas nos anos que antecedem os pleitos, momento em que o país começaria a ampliar a discussão sobre a sucessão desses cargos. Além disso, tentou-se, com o intervalo quadrienal, analisar edições da

\footnotetext{
${ }^{5}$ Importante esclarecer que a escolha dos parâmetros de análise se deu a partir do contato com o texto e como resultado do levantamento temático. Por exemplo, menções à participação de políticos, celebridades, gogo boys ou skinheads foram incluídas na categoria "caracterização dos participantes", enquanto falas reportadas, alocadas na categoria "discurso direto".
} 
Parada em cada um dos mandatos presidenciais (FHC, Lula, Dilma), o que permitiria observar se o avanço de políticas voltadas à comunidade LGBT ao longo dos anos traria alguma mudança nos sentidos de política produzidos nas notícias analisadas.

Neste trabalho, apresentamos um recorte relativo aos resultados da análise da categoria que nomeamos "caracterização dos participantes". A partir das considerações de Charaudeau (2013) sobre o signo semiolinguístico, detivemo-nos sobre a identificação de diferentes retomadas (nominais, sintagmáticas e pronominais) daqueles que tomam parte na manifestação, bem como sobre as formas de participação associada a esses indivíduos e grupos. Optamos, ainda, por dar atenção àqueles identificados como "não participantes", investigando de que forma a linguagem opera uma cisão entre os sujeitos do mundo (participantes / não participantes), criando igualmente fronteiras sobre a ação política.

Para que possamos empreender tal trabalho, é necessário definir algumas noções do aparato teórico da Análise do Discurso de que partimos. A mais imediata dela diz respeito ao poder de intervenção dos enunciados. De acordo com Rocha (2006), "os enunciados só representam o mundo no sentido de produzirem uma certa versão desse mundo, ou seja, de intervirem nesse mundo". Isso porque, como sustenta o autor, o discurso não poderia simplesmente representar o mundo, uma vez que não está distanciado dele. Assim, ao lidar com a matéria textual-discursiva, somos sempre apresentados a um retrato "sempre parcial de um dado momento, o retrato de uma realidade passada e/ou de uma nova paisagem que não coincide com as coordenadas geográficas de tudo o que pode ser verificado no "mundo vivo"” (ROCHA, 2014, p. 624).

Essa afirmação deve ser levada em conta, sobretudo, se tomarmos como objeto o discurso jornalístico, cujos objetivos são, precisamente, informar os cidadãos e reportar a "realidade", o fato. Nossa aposta, portanto, é de que não haveria representação de uma realidade, senão uma criação de realidade(s) provisória(s), instantâneas, através do movimento discursivo. Encontramos eco nas afirmações de Lagazzi-Rodrigues (2006), de que não haveria pensamentos e ideias anteriores à linguagem (em nosso caso, uma "política" ideal à qual a parada se filiaria ou não), nem língua independente dos sujeitos que a colocam em funcionamento (aqui, a relação jornal/leitores), nem um "colamento" das ideias e das coisas. Antes, o que haveria seriam sentidos e lugares de política que se 
fazem na matéria textual, através dos mecanismos linguístico-discursivos que ora nos propomos a investigar.

Disso, decorre que os sentidos não são matéria estável, dados pela língua em si; ao contrário, circulam socialmente e se dão na materialidade dos textos, não sendo transparentes nem frutos de um projeto plenamente consciente de dizer. Desse modo, a intenção do autor não é central nem dominante para que o sentido se realize. É preciso ter clara tal concepção para que não se incorra no engano de crer num trabalho de "interpretação", isto é, de busca por uma "verdade escondida", que se viria revelar, tampouco no desmascaramento de uma manipulação deliberada do sentido - afinal este não é de posse do autor.

Além disso, na esteira de Bakhtin (2004), tomamos a língua como um fenômeno dialógico, isto é, considerando que as palavras e enunciados estão atravessados pelo Outro, pelos usos que já se fizeram deles, bem como pelos que ainda se poderão fazer. O sentido, portanto, não é um dado, mas uma disputa que se faz a cada uso seu num texto. Sendo os textos construídos de uma malha discursiva, seria ilusório supor que apenas um sentido nele circule, donde a possibilidade de múltiplos sentidos para o político. Tal como sustenta Maingueneau (1996, p. 26), estamos diante de uma "verdadeira encruzilhada intertextual em que a palavra do enunciador é constantemente habitada por outras, tecida de seu eco". Ora, se é verdade que os textos se abrem para a polêmica, também o será afirmar, como o faz Lagazzi-Rodrigues (2006), que o texto é uma unidade ilusória, isto é, que seu fecho não passa senão de um efeito.

Ainda no caminho aberto pela noção de dialogismo linguístico, auxiliamo-nos em nossa análise dos mecanismos de pressuposição e subentendimento. Sobre os primeiros, retomando Ducrot, Maingueneau (1997, p. 79) afirma tratar-se de um processo que apresenta dois enunciadores (E1 e E2), sendo o segundo responsável pelo posto (o dito) e o primeiro, uma voz indefinida, atribuível à entidade abstrata "opinião pública", responsável pelo pressuposto. Este, aliás, é admitido como "uma instância que valida o significado" (MAINGUENEAU, 1997, p. 79). Já no lado dos subentendidos, o autor os define como o implícito "que se evidencia pelo confronto do enunciado com o contexto de enunciação", de modo que o conteúdo não está acessível imediatamente ao interlocutor, mas implícito, sendo necessário inferi-lo do enunciado (MAINGUENEAU, 2013). 
Finalmente, lançamos mão da análise de conectores argumentativos, à luz das discussões iniciadas por Ducrot (1987), cuja importância para a Análise do Discurso é retomada e sublinhada por Maingueneau (1997). A contribuição de Ducrot nesse quesito é importante porque pretende analisar o sentido dos operadores não a partir da correspondência dessas palavras a certas noções, mas fazer a indicação dos efeitos dessas palavras nos discursos em que são empregadas (DUCROT, 1987). Maingueneau (1997) reafirma tal importância de se trabalhar nas análises lexicais não só pelas estruturas sintático-enunciativas, mas também pela interdiscursividade. $\mathrm{O}$ interdiscurso "força estreitamente a interação entre o linguístico e o discursivo" (MAINGUENEAU, 1997, p. 152),

\section{Análise e discussão}

Ao longo dos anos, os atores da Parada LGBT são apresentados pela mídia por um lado através de um movimento generalizante dos indivíduos presentes (que corresponderiam discursivamente à totalidade dos participantes) e de outro, focalizando grupos ou indivíduos cujas ações são destacadas dos demais. Esse último procedimento é particularmente característico do discurso jornalístico do jornal em análise, como se observa no Manual de Redação da Folha de São Paulo, no verbete "Personagem da notícia":

\footnotetext{
Uma das formas de despertar o interesse do leitor é provocar identificação, ou empatia, com o personagem da notícia. Procure sempre levantar e registrar o máximo de informações (biográficas, físicas, de comportamento) sobre o entrevistado ou sobre os envolvidos no fato. Elas serão úteis no momento de descrever a pessoa (FOLHA DE SÃO PAULO, 1996).
}

Em 1997, a Folha de São Paulo apresenta somente um aspecto totalizante do evento: fala-se apenas de "pessoas", afastando-se de um recorte de gênero/sexualidade (homens, mulheres, gays, lésbicas, homossexuais etc) ou ideológico (manifestantes, cidadãos). Essas pessoas, por sua vez, são apresentadas através de dois movimentos: no título da reportagem, são reunidas pela parada ("Passeata gay reúne 400 pessoas em SP”, grifo nosso); no primeiro parágrafo, acompanham-na (“Cerca de 400 pessoas acompanharam ontem na avenida Paulista a $1^{\text {a }}$ Parada [...]”, grifo nosso). Conjugados, os termos auxiliariam na configuração de um evento anterior à presença das pessoas, ou 
seja, haveria uma parada prévia, constituída, que possuiria a qualidade de reunir pessoas, ao passo que estas não constituiriam a parada em si, mas apenas a acompanhariam. Observa-se, assim, uma objetificação das pessoas em relação à parada, pois esta parece ser o sujeito ativo que faz movimentar as pessoas. Ignora-se, desse modo, que a parada só se faz por se constituir de pessoas.

A análise do lexema "pessoas" nos permite perceber a importância da dimensão interdiscursiva no uso do vocabulário, pois de acordo com Maingueneau (1997, p. 155), “enunciar certos significantes, implica significar (nos dois sentidos da palavra) o lugar de onde os enunciamos".

Em 2001, novamente, a Parada é construída de acordo com sua qualidade de reunir pessoas ("Nas edições anteriores, a Parada reuniu 2000 pessoas (...)"), sendo que estas ora participam do evento, ora o acompanham. Relacionando este com o trecho anterior, temos formas semelhantes de "estar" na manifestação que sugerem um acontecimento que preexiste em relação aos participantes. Dito de outro modo, a Parada, no texto, existiria antes de seus integrantes, que viriam participar dela ou acompanhá-la, e não seria o resultado de uma reunião de indivíduos.

Mais adiante, na notícia de 2001, identificamos a seguinte sequência: “O principal motivo da manifestação era celebrar a liberdade de opção. E, por ela, misturaram-se jovens garotas de mãos dadas, drag queens, 400 voluntários, pais com filhos nos ombros, viúvas com cachorrinhos e muitas famílias" (grifo nosso). Parecenos clara neste trecho a ideia de intervenção da língua sobre a realidade: ao propor que garotas, drag queens, voluntários, famílias, etc. "se misturaram" pela "liberdade de opção”, o jornal parece criar um mundo no qual haveria uma divisão prévia, pressuposta pelo verbo "misturar-se": a de que todos esses elementos (jovens garotas, drag queens, voluntários, pais, fillhos, viúvas e famílias) não estão misturados habitualmente ou, no mínimo, não pertenceriam à mesma realidade.

Esse recorte de realidade feito pelo jornal nos remete a uma abordagem de semântica descritiva feita em meados da década de 1950, que consistia quase sempre em assimilar semântica e estudo do léxico, como declara Ducrot (1987, p. 45): “o semanticista, nesta perspectiva, era aquele que tentava definir o sentido das palavras".

Não é trivial, aliás, que esses elementos sofram recortes aparentemente diversificados, que versem sobre a diversidade de gênero (garotas), a diversidade sexual 
(ou mesmo a arte, no caso das drag queens), a constituição familiar (viúvas, pais com filhos nos ombros, famílias), o trabalho (voluntários). A partir do movimento discursivo, portanto, cria-se um mundo provisório, recortado dos "dados sensíveis do real", no qual meninas de mãos dadas não seriam exatamente voluntárias, pais com filhos nos ombros não seriam exatamente famílias, dentre outros.

Dentre os participantes "focalizados", figuram alguns, contudo, que, também por um movimento discursivo, são apresentados como elementos inusitados dentro do contexto da Parada. Ainda em 2001, encontra-se a sequência: "Com a animação da parada, um travesti chegou a subir e dançar no alto de um guindaste de um caminhão da Eletropaulo (...)" (grifo nosso). Ao focalizar esse modo de participação, destacando-o com a locução "chegar a", o jornal parece apontar e reforçar uma cisão entre comportamentos esperados e comportamentos não esperados para a parada. Não se imaginaria, por exemplo, uma locução semelhante em ações que poderiam ser consideradas "normais" e "naturais", como "um manifestante chegou a discursar no alto de um carro de som" ou "meninas chegavam a dançar debaixo do sol”. Por essa razão, seria possível sustentar que a locução "chegar a" contribuiria para uma cristalização de comportamentos esperados e, por consequência, na própria parada. Nesse sentido, há coerções na língua que regem esta apresentação de mundo, parafraseando Ducrot (1987).

Finalmente, no último parágrafo da notícia de 2001, o jornal destaca: “Até dois zapatistas solitários, que se diziam heterossexuais, desfilaram atrás do último carro, empunhando uma faixa contra o capitalismo". Para além do destaque da presença desses dois rapazes (num universo de mais de duzentas mil pessoas), chama a atenção que o termo "zapatistas" seja substantivado, identificando-os com um rótulo que remeteria a um embate político.

É também notório que sua presença seja ressaltada através do uso do conectivo argumentativo "até", que mobiliza um implícito que seria o de não admitir que a presença dos zapatistas seria habitual no evento. Apesar de o operador argumentativo “até” não ser objeto de análise de Ducrot (1987) e Maingueneau (1997), consideramos que sua análise deve ultrapassar a classificação prescritiva que recebe nas gramáticas, cuja classificação se restringe à classe dos adjetivos, embora haja, em algumas gramáticas, tais como a "Nova Gramática do português contemporâneo", de Celso 
Cunha e Lindley Cintra (2007), a classificação de "palavras denotativas de inclusão" para : até, inclusive, mesmo, também.

Seguindo a linha de argumentação da análise da abordagem do personagem anterior, os "zapatistas" são apresentados como elementos surpreendentes no universo textual da parada criado pelo jornal. E se há elementos surpreendentes, estaria subentendido que os demais elementos seriam naturais ou, no mínimo, esperados, de modo a se criar uma desidentificação do acontecimento "parada" com os aportes trazidos pelos dois rapazes, ou seja, o discurso do jornal investe na criação de uma realidade do evento que separa a política da "festa".

Também não é trivial o modo como eles são apresentados. Além do uso do conectivo supracitado, o jornal ressalta a localização espacial dos rapazes com relação à manifestação (“atrás do último carro"), adjetivando-os inclusive como "solitários". Ademais, sua presença é marcada no último parágrafo da página. Considerando as teorias jornalísticas do espaço redacional, segundo as quais os elementos menos relevantes no contexto da notícia são apresentados por último, haveria também um efeito de isolamento dos jovens frente ao contexto da manifestação. Assim, uma nova divisão é empreendida no movimento textual: um grupo cujas reivindicações (de cunho mais marcadamente político) parecem diferir das demais.

Em 2005, são menos frequentes as remissões ao conjunto dos participantes, referidos primordialmente como "pessoas", em conotação generalizante. Ainda assim, persiste a ideia de um acontecimento prévio: a manifestação "tem" 1,8 milhões de pessoas.

Diferente do ano anteriormente analisado, surge nas reportagens de $2005 \mathrm{um}$ termo novo para se referir a determinados participantes: militantes. No subtítulo da notícia, estes são opostos à polícia na quantificação do público (“Segundo a Polícia, o evento teve 1,8 milhão de pessoas; militantes falavam em 2,5 milhões"); posteriormente, o termo é usado como adjetivo ("uma drag queen militante do Grupo Gay da Bahia proclamava a proeza: 'Já somos 2,5 milhões na avenida. Este é o novo recorde mundial de uma parada gay""); mais à frente, enfim, o termo é novamente substantivo, ao se lançar o foco sobre militantes do PT que teriam distribuído camisetas de campanha para Marta Suplicy ("Militantes do PT distribuíram camisetas com a inscrição "Marta 2006”"). Em comum, o fato de que os "militantes" só aparecem em 
contextos institucionalizados - militantes de tal ou qual grupo - apontam para uma política institucionalizada. É de se notar igualmente que o enunciador no segundo trecho trazido é referido como uma drag queen (anônima) que demanda o qualificador militante (do Grupo Gay da Bahia), pressupondo uma desassociação entre os termos há drag queens não militantes (ou, minimamente, caracterizar-se como drag queen não é condição suficiente para ser considerado militante, sendo necessária a adjetivação nesse contexto).

Corrobora essas observações a ideia de que as ações dos "militantes" se limitam a uma contagem de público e à distribuição de material de campanha. Além disso, no plano do não dito, é interessante observar que o termo não se aplica, em nenhuma das reportagens analisadas, à totalidade dos participantes, o que poderia sugerir uma ação diferenciada da "militância". Quando têm suas ações narradas, por sua vez, os demais participantes recebem referentes que vão do geral ao específico, como "gays homens", "fãs", "casais, duplas e trios", "dois amigos", "presidenta da Amam", etc, e que não parecem apontar para uma política prototípica. O mesmo se poderia dizer para suas formas de participação relatadas pelo jornal: gays homens urinam na rua, fãs gritam histericamente, casais, duplas e trios usam fantasias, dois amigos vão à Parada caracterizados de certa maneira, a presidenta da Amam impede a entrada de um homem num trio elétrico.

Faz-se uma ressalva, contudo, ao uso do referente "manifestantes", que no ano em questão surge em apenas um contexto, evocado na sequência "Aqui e ali, ontem, viam-se manifestantes fumando um cigarro de maconha, enquanto dançavam ao som de Gloria Gaynor, Ivete Sangalo, Cazuza e Cassia Eller”. Apesar de aludir a uma política prototípica (é possível atribuir o nome "manifestantes" àquele grupo pessoas), é notável que o termo se insira no contexto da seguinte sequência: "Foi uma enorme brincadeira, regada a litros e mais litros de cerveja, whisky falsificado e vinho barato". Que relação lógica torna possível fazer referência a uma brincadeira e evocar manifestantes fumando maconha logo em seguida? Iluminam-se algumas possibilidades: uma nova configuração da ideia de manifestação, na qual é possível brincar e se manifestar ao mesmo tempo? Um enfraquecimento da ideia de manifestação? Em todo caso, "manifestar", aqui, adquire sentidos não transparentes, recuperados através do próprio fato da possibilidade de se enunciar. 
No que diz respeito a figuras da política partidária, é também interessante observar certo apagamento, que tensiona as possibilidades de modos de participação do público na Parada LGBT. Ao trazer as figuras de José Serra e Marta Suplicy, o jornal os coloca em posição de agentes que "recebem" determinados protestos. Contudo, não se atribui a responsabilidade de tais manifestações a um agente (“Ao subir ao palco, Serra recebeu vaias e aplausos" / "Ela também recebeu alguns protestos"). Note-se, inclusive, que o teor de tais manifestações é diferenciado: para José Serra, "vaias e aplausos"; para Marta, "alguns protestos". Longe de serem sinônimos, os termos podem ter entre si uma ligeira nuance de sentidos, ressaltando neste um aspecto negativo.

Ao lado dos participantes humanos, outro se faz perceber em meio ao relato do jornal, na seguinte sequência: “A poucos metros dali, o caixa eletrônico do banco Itaú se transformou num 'darkroom' - sala escura, em inglês, típica dos clubes gays". Personificado, o caixa eletrônico (metonímia para o espaço do banco) é agente de uma transformação, tendo suas funções atualizadas. Em meio a um contexto em que a cidade se "transforma", o espaço é apresentado como um dos ambientes dos clubes gays, o que sugere um efeito de mercantilização do evento, por extensão: se o caixa eletrônico do banco é o darkroom, a Parada seria a própria pista de dança. Com isso, através do movimento textual, os participantes e manifestantes em potencial parecem passar a frequentadores de um clube noturno, com todos os seus ambientes: a própria Parada.

Encerrando a cobertura da edição, o jornal dedica um box à direita da página para tratar de um novo e aparentemente inusitado "personagem". Com o subtítulo "Gay 'separatista' prefere festa a desfilar na parada”, o jornal dispõe:

\footnotetext{
Muito exibido, mas com ressalvas. Assim é o personal trainer Rogério Antônio da Silva, 35, que recebeu a Folha ontem para acompanhá-lo nos preparativos para a Parada Gay e numa festa diurna no Conjunto Nacional, na avenida Paulista.

Silva fez até fotos tomando banho, mas pediu para não ser associado a "bichinhas estereotipadas". Na sua própria definição, Silva é um "gay com cabeça de hétero": disse que frequenta reuniões de donos de Tigra, seu carro, gosta de esportes radicais e faz boxe.

Ele diz que poucas pessoas sabem que ele é gay. Silva se recusou a posar para fotos ao lado das "pintosas", afirmou que não fazia a menor questão de ser associado "àquelas pessoas". Só quando subiu à festa regada a champanhe disse: "Esse é o meu ambiente" (...)
}

O jornal apresenta ao leitor Rogério Antônio da Silva, identificado na chamada da reportagem como "gay 'separatista"”. Tendo em vista as análises empreendidas, o 
primeiro dado a ser observado é a adjetivação do termo que evocaria o embate político, diferente do substantivo empregado para se referir aos "zapatistas" em 2001.

Ao tratar o personal trainer sob essa alcunha, o leitor poderia recuperar um sentido de disputa política territorial - o separatismo. Com efeito, é interessante observar a criação de uma separação espacial discursiva entre a "Parada" (rua) e a "festa" (no Conjunto Nacional). Numa leitura primária, seria possível supor uma oposição festa $x$ desfile como uma preferência de Rogério da Silva por um ambiente mais festivo em comparação a outro menos festivo - afinal, pressupõe-se pela oposição estabelecida no título que "desfilar na parada" não é o mesmo que "festa" e que é possível (e talvez necessário) optar por um ou por outro.

Contudo, o que nos revela uma leitura mais atenta da reportagem é que a oposição se dá entre duas festas de atributos diferentes. À festa no Conjunto Nacional, atribuem-se os qualitativos [+cabeça de hétero], [+champanhe], [+roupas de grife]; à Parada, os qualitativos [+bichinhas estereotipadas]; [+pintosas $\left.{ }^{6}\right]$. À luz desse embate, parece haver um esvaziamento de sentidos políticos da Parada, que pertence a um universo textual em que pode ser comparada (e oposta) a uma festa particular. Apagando a possibilidade de outros sentidos para a Parada, ao menos nessa passagem, o jogo de oposições, portanto, construiria um mundo ético no qual a única diferença entre a parada e uma festa se pauta em valores de consumo e comportamento mais ou menos heteronormativo.

Em 2009, já não se alude à totalidade dos participantes como "manifestantes". Contudo, volta à cena o termo "militantes", empregado logo no início da notícia: "A produção do clima de festa [devido à ausência de carros de boates] ficou, então, nas mãos dos carros de militantes". Com o uso do artigo definido no sintagma "clima de festa", ambienta-se a Parada como um dado, sem que para isso seja necessário afirmar que havia um clima de festa. Além disso, um pressuposto chama a atenção: para ser possível enunciar que, neste ano, o clima de festa era produzido por militantes, termo substantivado, seria necessário pressupor que, nos anos anteriores, ele seria realizado por "não militantes". Mais do que reportar a realidade, através da enunciação, cria-se uma memória discursiva ${ }^{7}$ dos anos anteriores do evento: se somente nesse ano o clima é

\footnotetext{
${ }^{6}$ Na gíria gay, "pintosa" é o homossexual afeminado, afetado, que "dá pinta" [de gay], indícios evidentes de sua orientação sexual.

${ }^{7}$ Moirand (1999, apud CHARAUDEAU; MAINGUENEAU, 2012)_sustenta o poder de constituição " $n a$
} 
produzido por "militantes", subentende-se que antes ele seria produzido por outros indivíduos e grupos que não se poderiam qualificar dessa forma. Através do jogo de pressupostos, a notícia discorre não apenas sobre o presente, mas sobre o passado, recuperando e, paradoxalmente, criando memória.

Com efeito, as notícias de 2009 seguem a prática da reportagem de 2005, a de considerar "militante" apenas o indivíduo "institucionalizado", de organizações, partidos, etc. Logo em seguida, o jornal apresenta sua definição para o termo: "grupos engajados não apenas em causas especificamente gays, mas em defesa do ambiente e da igualdade racial, além da promoção de igrejas e sindicatos".

A outros participantes, "não militantes", são atribuídos lugares bastante específicos, que apontam para certa territorialização do evento: “(...) no trio da drag queen Salete Campari, um dos mais festejados do desfile, com artistas como Rogéria, Leão Lobo e grande presença de go go boys (dançarinos sem camisa, em geral de sunga branca)". No trecho, a participação de artistas é mencionada como uma presença celebrada pelos participantes. O jornal ainda faz referência ao trio elétrico da drag queen Salete Campari, que contém artistas como Rogéria e Leão Lobo, sugerindo uma passividade em seu modo de participação, bastando somente a constatação de sua presença para a realização de um ato.

Logo em seguida, referente aos "go go boys" citados, lê-se: "esses rapazes descamisados, as drag queens e outros artistas dividiam espaço com mensagens de engajamento". No enunciado em questão, observa-se uma oposição sutil sendo colocada e, mais, um espaço a ser dividido - de um lado, drag queens e artistas; de outro, mensagens de engajamento, sem qualquer especificação e apresentadas como dados evidentes por si. Sugere-se, assim, através do uso do verbo, que go go boys, drag queens e demais artistas apareçam como "mensagens de desengajamento", ou ao menos algo distante de um "verdadeiro engajamento", borrando a possibilidade do corpo como política. Tal como apontado no episódio do "gay separatista", através de um movimento discursivo, criam-se fronteiras no universo da Parada. Aqui, uma divisão de lugares nos quais ocorreria a política (o engajamento) e outros nos quais ocorreria qualquer outra coisa, cuja natureza nos escapa, mas que parece apontar para a arte (de go go boys e drag queens) como um lugar de não política. Reforçamos aqui a ideia de intervenção da

e pela mídia" de uma memória capaz de permitir um regime de alusão, participando da interpretação dos acontecimentos. 
linguagem no mundo.

Outro momento no qual se vislumbra essa cisão no evento, criando efeitos de sentido acerca do político, encontra-se no trecho: "Espinha dorsal do evento, o ativismo gay ficou parado em boa parte do evento". A metáfora do corpo sugere uma centralidade do ativismo na Parada (mudança de perspectiva notável em relação aos anos anteriormente analisados). Entretanto, essa centralidade é matizada, uma vez que o ativismo é personificado e ganha o atributo [-movimento], sugerindo que o "ativismo" seja um dado localizável - e não disperso pela Parada em si. Dá sustento a essa visão considerar que, logo em seguida, na notícia de 2009, o jornal traz em discurso direto a voz de "um representante", anônimo, impessoal, que convoca os participantes para a assinatura, deixando pouco clara sua relação com o evento: “'Queremos sair daqui com um milhão de assinaturas', bradava um representante ao microfone".

Ao final da segunda notícia, o jornal relata um caso de violência: "No episódio mais grave, por volta das $22 \mathrm{~h}$, o morador de um edifício na avenida Vieira de Carvalho (centro) se irritou com o barulho de pessoas que se dispersavam da festa e jogou uma bomba caseira no grupo". O trecho em questão parece criar para esse indivíduo um lugar de "não participação", ou, minimamente, de "participação contrária". É possível vislumbrar no relato uma cena de embate, na qual o "morador" é oposto à "festa". Quanto às ações dos participantes, encontram-se a de "dispersar" de uma festa e "fazer barulho", relatados como elementos provocadores da irritação alheia, numa relação de causa e consequência.

Em 2013, o jornal confere amplo destaque para a diminuição no número de participantes dessa edição, graças a métodos estatísticos próprios (Instituto Datafolha). Diz o título da notícia: "Parada Gay encolhe e leva 220 mil às ruas de São Paulo".

Com relação às demais notícias analisadas, é perceptível a ausência de termos que apontariam, a priori, para sentidos mais estabilizados de política, no que se refere à totalidade dos participantes - como nos anos anteriores houve, por exemplo, "manifestantes". Nas três notícias que compõem o ano em questão, encontram-se os termos "público", "pessoas", "multidão", sugerindo uma homogeneidade que tende ao pacífico, apagando disputas.

Ainda assim, é possível vislumbrar em certos enunciados algumas torções à questão política. Referindo-se à diminuição no número de manifestantes, o jornal 
apresenta como causas a chuva e o clima frio: "a chuva persistente e a temperatura média de $16^{\circ} \mathrm{C}$ afastaram o público da Parada Gay de São Paulo neste ano". Nessa relação de causa e consequência (chuva $\rightarrow$ menos público), poderia subentender-se que a principal razão para o comparecimento dos indivíduos à Parada seria o bom tempo, borrando outras possibilidades.

Essa constatação é reforçada ao se analisar um enunciado mais à frente, no qual a voz do jornalista afirma: "pelo jeito, o público não estava nem aí para 'lutas' num dia frio e chuva". Introduzido por uma expressão que denota posição conclusiva com relação ao fato ("pelo jeito"), observa-se uma gradação de relevância para participação na Parada, na qual a luta seria considerada menor se comparada ao clima. Desse modo, o leitor estaria diante de um mundo ético, criado pelo jornal, no qual o mau tempo seria razão suficiente para afastar os indivíduos da participação e, portanto, da ação política. O uso de aspas no substantivo "lutas" é também digno de nota no trecho em questão, ao recuperar (com alto grau de afastamento) o sentido atribuído ao termo pela fala de duas travestis entrevistadas: "A parada é um movimento que tem como objetivo a luta pelos direitos da comunidade LGBT (Lésbicas, Gays, Bissexuais, Travestis e Transgêneros)" e "É uma força política forte. Quem quer lutar pela diversidade vem para cá". Colocamse em cena ao menos dois sentidos de "luta"/"política": aquele proposto pelas entrevistadas e outro que o rejeita, proposto pelo jornalista.

Como nos anos anteriores, a participação de figuras da política partidária é também sublinhada através da simples presença: Geraldo Alckmin, Fernando Haddad, Jean Wyllys, dentre outros, estiveram no evento, forma de participação aparentemente passiva. Entretanto, Daniela Mercury se destaca nesse contexto. Na terceira notícia do ano, parece-nos relevante destacar um dos verbos associados à cantora, criadora de sentidos para toda a Parada. Na manchete, o jornal afirma: "Daniela esquenta parada fria e chuvosa", caracterização que pressuporia dois estados: um anterior [+frio] e [+chuvoso] e outro posterior à presença da cantora [+quente].

Contudo, tais caracterizações não nos parecem simples indicações meteorológicas, sugerindo, antes, valores para a manifestação - [+desânimo] x [+animação]. Efetivamente, pouco em seguida, o jornal afirma: “o 'tum-tum-tum' dos trios elétricos até que tentou esquentar a Parada Gay, mas quem atiçou a galera foi mesmo a cantora Daniela Mercury". Ainda que o leitor não tenha acesso às ações 
anteriores ao show da artista, seria possível inferir um antes (frio, chuvoso, desanimado) e um depois (quente, atiçado, animado) do estado de espírito dos manifestantes, transformado graças à presença da artista.

Quanto às formas de participação de outros personagens, vale destacar, ainda, alguns enunciados que põem em cena participantes não inseridos no contexto imediato dessa edição da Parada. Na notícia, cria-se uma memória discursiva acerca de outros eventos e participantes.

É o caso da Parada Gay de Salvador. Tematizando a presença de Daniela Mercury, a notícia ressalta: "o governo baiano investiu 120 mil reais no trio elétrico da cantora, como parte de uma ação que visa transformar a Parada Gay de Salvador na segunda maior de todo o país". Não é dado ao leitor saber de que maneira o jornal teve acesso a tal informação, até porque esse quesito não é característico do gênero jornalístico, ainda que ele só possa ser realizado por meio de enunciados, em sentido amplo (notas oficiais? Pronunciamentos de prefeitos? Coletivas de imprensa?). Ainda assim, o "governo baiano" desponta na Parada de São Paulo também como participante, tendo como ação "investir" no trio elétrico. É relevante notar o emprego do verbo "investir", remetendo aos supracitados aspectos mercadológicos do evento. Questionamos: por que somente o "investimento" desse carro é destacado? Afastandonos da ideia de intencionalidade do jornalista, nossa aposta é que o destaque, e, portanto, o apagamento das demais possibilidades, é criador de sentidos, e sugeriria uma política que passa por questões financeiras, associando a política ao investimento investe-se para transformar a Parada de Salvador... mas e os demais carros? Por que investem?

Ao lado desse, outro personagem ganha destaque, também caracterizado por sua não participação. Diante da fala de Daniela Mercury, reportada pelo jornal ("Fora, Feliciano. Eu quero é felicidade"), o jornal recupera vozes que parecem situar o pastor Marco Feliciano no contexto da luta LGBT. Numa delas, o religioso desponta como "o principal alvo da parada de ontem, tanto no chão como no alto dos trios elétricos". Dois dados chamam a atenção: o primeiro, a remissão ao fato de Feliciano ter sido o "principal" alvo da Parada, pressupondo a existência de outros "alvos", que, no entanto, são apagados. O segundo, a ideia de "territorialização" da Parada (alto dos trios x chão), apontando para locais distintos, nos quais circulariam práticas distintas (a ponto de ser 
necessário destacar que o "alvo" em comum, de certa maneira, os uniu). Mais uma vez, sugere-se através do movimento discursivo que haveria lugares distintos na Parada, nos quais circulariam ações mais marcadamente políticas e outras, aparentemente, que tendem a se afastar dela, de um modo ou de outro.

\section{Considerações finais}

Em razão de nossas escolhas metodológicas, foi preciso descartar uma gama de materiais que poderiam contribuir em grande medida com a ideia da criação de fronteiras entre participantes da Parada LGBT. Entre eles, destacamos imagens, legendas, abordagens estatísticas, etc., as quais podem ser fruto de publicações futuras sobre o tema.

Neste trabalho, através da análise de nominalizações e de diferentes formas de participação dos indivíduos e grupos ao longo das notícias, observamos uma rede de pressuposições que aponta para sentidos territorializados e localizados da política que circula na Parada. Em nossa investigação, pudemos constatar enunciados que parecem restringir ações políticas a determinados espaços, indivíduos e ações, apagando ora modos diversos de se fazer política (através do corpo, através da ocupação de espaços, através do afeto), ora ações ditas prototipicamente politizadas.

Através desta leitura, sugerem-se novas evidências para a ideia de que o discurso jornalístico, antes de "relatar" um fato, o produz. Recusa-se, assim, o primado da informação, no qual a língua estaria colada à realidade à qual faz referência. Em sentido diverso, a aposta de nossa perspectiva passa pelo descolamento (ou, ao menos, por uma desnaturalização) do par "língua / realidade".

O que se tem, ao fim e ao cabo, é uma concepção de língua que diz sempre mais e sempre menos. Mais, porque não há somente uma "informação" sendo veiculada em textos - haveria, além, mundos possíveis a serem criados, mundos éticos nos quais a enunciação que, paradoxalmente, legitimam e são legitimados pela própria enunciação. Menos, porque o que chamamos de realidade escapa à captura da língua, não sendo possível, portanto, apurá-la por "completo". A sensação de completude parece, portanto, também ela arbitrária. 


\section{REFERÊNCIAS}

BAKHTIN, M. Marxismo e Filosofia da Linguagem. São Paulo: Hucitec, 2004.

BUTTERMAN, S. (In)visibilidade vigilante: representações midiáticas da maior parada gay do planeta. São Paulo: NVersos, 2012.

CARRARA, S. As paradas do orgulho GLBT no Brasil e a construção de mundos possíveis. In: NETTO, F. C.; FRANÇA, I. L.; FACCHINI, R. (Org.). Parada: 10 anos do Orgulho GLBT em SP. São Paulo: Editora Produtiva, 2006, p. 68-69

CHARAUDEAU, P. Discurso das mídias. $2^{\mathrm{a}}$ ed. $2^{\mathrm{a}}$ reimpressão. São Paulo: Contexto, 2013.

2014.

Linguagem e discurso: modos de organização. $2^{\mathrm{a}}$ ed. São Paulo: Contexto,

COTTA, D.; CABRAL FILHO, A. V. Parada do Orgulho LGBT: uma estratégia midiática de visibilidade cultural. Políticas Públicas \& Cidades, v. 4, n. 3, p. 26-41, 2015.

CUNHA, C.;CINTRA, L. A Nova Gramática do Português Contemporâneo, $3^{\mathrm{a}}$. Ed. Rio de Janeiro: Lexikon, 2007.

DUCROT, O. O dizer e o dito. Campinas: Pontes, 1987.

FACCHINI, R. Sopa de letrinhas? Movimento homossexual e produção de identidades coletivas nos anos 90. Rio de Janeiro: Garamond, 2005.

Histórico de Luta de LGBT no Brasil. In: CONSELHO REGIONAL DE PSICOLOGIA DA $6^{\mathrm{a}}$ REGIÃO (Org.). Psicologia e diversidade sexual. São Paulo: CRPSP, 2011. p. 10-19.

FACCHINI, R.; FRANÇA, I. L. De cores e matizes: sujeitos, conexões e desafios no Movimento LGBT brasileiro. Sexualidad, salud y sociedade, n. 3, p. 54-81, 2009.

FOLHA DE SÃO PAULO. Novo manual da redação - 1996. Disponível em: < http://www1.folha.uol.com.br/folha/circulo/manual_producao_p.htm>. Acesso em: 24 out. 2017

29 jun. 1997.

Passeata gay reúne 400 pessoas em SP. Folha de São Paulo. São Paulo, p. 4.

Parada Gay registra recorde de público. Folha de São Paulo. São Paulo, caderno Cotidiano, p. C1. 18 jun. 2001.

Parada Gay tem ampla presença feminina. Folha de São Paulo. São Paulo, caderno Cotidiano, p. C1. 30 mai. 2005a.

. "Siameses" usam roupas iguais em parada. Folha de São Paulo. São Paulo, 
caderno Cotidiano, p. C8. 30 mai. 2005b.

Sem trios de boates, política avança na Parada Gay de SP. Folha de São Paulo. São Paulo, caderno Cotidiano, p. C1. 15 jun. 2009a.

Brigas, furtos e até bomba prejudicam clima de festa. Folha de São Paulo. São Paulo, caderno Cotidiano, p. C3. 15 jun. 2009b.

Parada Gay encolhe e leva 220 mil às ruas de São Paulo. Folha de São Paulo. São Paulo, caderno Cotidiano, p. C1. 03 jun. 2013a.

Maioria tem parceiro, mas não é casada. Folha de São Paulo. São Paulo, caderno Cotidiano, p. C4. 03 jun. 2013 b.

Daniela esquenta parada fria e chuvosa. Folha de São Paulo. São Paulo, caderno Cotidiano, p. C5. 03 jun. 2013c.

Missão, visão, princípios e valores. s/d. Disponível em: < http://www1.folha.uol.com.br/institucional/missao.shtml>. Acesso em: 21 jun. 2016.

INSTITUTO VERIFICADOR DE COMUNICAÇÃO. Posição, participação $e$ evolução das publicações. São Paulo, 2015. Mimeografado.

LAGAZZI-RODRIGUES, S. Texto e autoria. In: ORLANDI, E; LAGAZZIRODRIGUES, S. Discurso e textualidade. Campinas: Pontes, 2006.

MACHADO, F. V.; PRADO, M. A. M. Visibilidade, sexualidade e cidadania na Parada do Orgulho LGBT de Belo Horizonte. Seminário Nacional Movimentos Sociais, Participação e Democracia. 2. Anais... Florianópolis: EDUFSC, 2007.

MAINGUENEAU, D. Pragmática para o discurso literário. Trad. de Marina Appenzeller. São Paulo: Martins Fontes, 1996.

Novas tendências em Análise do Discurso. Trad. Freda Indursky. $3^{\text {a }}$ ed. Campinas: Pontes: Editora da Universidade Estadual de Campinas, 1997.

Análise de textos de comunicação. Trad. Maria Cecília P de Souza-e-Silva e Décio Rocha. $6^{\text {a }}$ ed. ampl. São Paulo: Cortez, 2013.

PARIS, G. S. Parada do Orgulho LGBT no Rio de Janeiro: um desfile-mobilização e suas estratégias comunicativas. 2015. 156 f. Dissertação (Mestrado em Comunicação e Cultura) - Escola de Comunicação, Universidade Federal do Rio de Janeiro, Rio de Janeiro. 2015.

RAMOS, S.; CARRARA, S. A constituição da problemática da violência contra homossexuais: a articulação entre ativismo e academia na elaboração de políticas públicas. Physis, Rio de Janeiro, v. 16, n. 12, p. 185-205, 2006.

RIBEIRO, D. Stonewall: 40 anos de luta pelo reconhecimento LGBT. In: COLLING, L. (Org.) Stonewall $40+$ o que no Brasil? Salvador: EDUFBA, 2011. 282p. (Coleção 
CULT; n. 9)

ROCHA, D. Representação e intervenção: produção de subjetividade na linguagem. Gragoatá. Niterói: Ed. UFF, v. 21, p. 355-372, 2006.

Representar e intervir: linguagem, prática discursiva e performatividade. Linguagem em (Dis)curso - LemD, Tubarão, SC, v. 14, n. 3, p. 619-632, set./dez. 2014.

TREVISAN, J. S. A parada do amor continua. In: NETTO, F. C.; FRANÇA, I. L.; FACCHINI, R. Parada: 10 anos do Orgulho GLBT em SP. São Paulo: Editora Produtiva, 2006. p. 14-15. 